\title{
Abiotic Stress Response of Field Crops: Recent Approach
}

\author{
Pratibha Kumari ${ }^{1 *}$, Reena Kumari ${ }^{2}$, Babloo Sharma ${ }^{3}$, \\ Saroj Kumar Prasad ${ }^{4}$ and Rajesh Kumar Singh ${ }^{4}$
}

\author{
${ }^{1}$ Department of Soil Science \& Agricultural Chemistry, ${ }^{4}$ Department of Agronomy, \\ Institute of Agricultural Sciences, Banaras Hindu University, \\ Varanasi-221005, Uttar Pradesh, India \\ ${ }^{2}$ Department of Agricultural Engineering, N.M. College of Agriculture, Navsari Agricultural \\ University, Navsari - 396450, Gujarat, India \\ ${ }^{3}$ Krishi Vigyan Kendra (Swami Keshwanand Rajasthan Agricultural University), Pokhran, \\ Jaisalmer-345021, Rajasthan, India \\ *Corresponding author
}

\section{A B S T R A C T}

\section{Keywords}

Heat stress, Drought stress, Salinity,

Crops, Agricultural production

Article Info

Accepted:

15 March 2019

Available Online:

10 April 2019

\begin{abstract}
Abiotic stresses such as drought, salinity, heat and cold, are greatly affecting the plant growth and agricultural productivity and causes more than $50 \%$ of worldwide yield loss of major crops every year. It is a major global problem that limits crop productivity. Yield potential of modern cultivars is limiting by stress factors. These stresses are increasing because of the declining availability of good quality water, land degradation and pollution. In the plant, stress results in nutritional imbalances causing a reduction in water uptake and an increase in toxicity, decreasing the product. In many parts of the world salinity and drought are the major abiotic stresses that limit and pose a threat to agricultural production. These stresses are interconnected as osmotic stress, resulting in the disruption of ion distribution and homeostasis in the cell. In India, abiotic stresses are the primary cause of crop failures. Hence, it is necessary for the adoption of the stress response mechanism in field crops.
\end{abstract}

\section{Introduction}

Abiotic stress includes potentially adverse effects of Salinity, Drought, Flooding, Metal toxicity, Nutrient deficiency, High temperature and Low temperature. In addition, abiotic stresses can include Shade, UV exposure, Photo inhibition, Air pollution,
Wind, Hail and Gaseous deficiency which are often sporadic and highly localized in occurrence. In some cases, such as the supply of water, too little (drought) or too much (flooding) can both impose stress on plants. In plant growth abiotic stress is already a major limiting factor and will soon become even more severe as desertification covers more 
and more of the world's terrestrial area, in the era of the increased salinization of soil and water and a global scarcity of water resources. In the deterioration of the environment, drought, extreme temperatures, salinity, chemical toxicity, and oxidative stress are serious threats to agriculture. Worldwide average yields of major crop plants are reducing by more than $50 \%$ due to abiotic stress (Bray et al., 2000). Drought and salinity are becoming particularly widespread in many regions, and may cause serious salinization of more than $50 \%$ of all arable lands by the year 2050 (Machado and Serralheiro, 2017). In the world, where population growth exceeds food supply, agricultural and plant biotechnologies aimed at overcoming severe environmental stresses need to be fully implemented. Serving as the interface between the plant and the soil, roots are more exposed to many abiotic stresses than the aerial parts of the plant; for example, drought, waterlogging, and salt stress (Wells and Eissenstat, 2003).

In contrast to plant resistance to biotic stresses, which is mostly dependent on monogenic traits, the genetically complex responses to abiotic stresses are multigenic, and thus more difficult to control and engineer. Plant engineering strategies for abiotic stress tolerance (Wang et al., 2003) rely on the expression of genes that are involved in signaling and regulatory pathways (Shinozaki et al., 2003) or genes that encode proteins conferring stress tolerance (Wang et al., 2004) or enzymes present in pathways leading to the synthesis of functional and structural metabolites. The major aspects of abiotic stress in plants are discussed (Figure $1)$.

\section{Types of abiotic stress in plants}

Various types of abiotic stresses that plants encounter between seedlings to harvest stages are:
Irregular and uncertain rainfall

Abundant and copious soil moisture or its quick retreat

Soil salinity

Micronutrient (soil nutrition) shortage in the root zone

Global change in weather patterns

Economic and political uncertainty

\section{Abiotic stress situation}

Fundamentally, for the proper growth plants require energy (light), water, carbon and mineral nutrients. Abiotic stress can be defined as environmental conditions which reduce growth and yield below optimum levels. Plant responses to abiotic stresses are dynamic and complex (Skirycz and Inze, 2010); they are both elastic (reversible) and plastic (irreversible) (Figure 2). Plant growth is affected by reducing water uptake into the expanding cells under Water deficit condition, and alters enzymatically the rheological properties of the cell wall; for example, by the activity of ROS (reactive oxygen species) on cell wall enzymes (Skirycz and Inze, 2010). In addition, water deficit alters the cellwall non enzymatically; for example, by the interaction of pectate and calcium (Boyer, 2009). Furthermore, water conductance to the expanding cells is affected by aquaporin activity and xylem embolism (Parent et al., 2009). The initial growth inhibition by water deficit occurs prior to any inhibition of photosynthesis or respiration (Hummel et al., 2010). A series of morphological, physiological, biochemical and molecular changes occur due to abiotic stress which adversely affect the plant growth and productivity (Wang et al., 2001). Drought, salinity, extreme temperatures and oxidative stress are often interconnected, and may induce similar cellular damage. For example, drought and/or salinization are manifested primarily as osmotic stress, resulting in the disruption of homeostasis and ion distribution 
in the cell (Zhu, 2001). High temperature, salinity or drought stress, frequently cause to Oxidative stress, that may cause denaturation of functional and structural proteins (Smirnoff, 1998).

Tissue dehydration occurs when there is an imbalance between root water uptake and leaf transpiration (Aroca et al., 2001). When leaves begin to dehydrate plants generally start closing their stomata; however, under some environmental situations or in specific plant genotypes, modification of root water uptake capacity plays a more important role compared with stomatal closure in avoiding stress-induced growth reduction (Matsuo et al., 2009).

The importance of root water uptake capacity in coping with several abiotic stress conditions is supported by the work of Aroca et al., (2001) who found that two maize genotypes differing in chilling sensitivity also differed in the response of their root water uptake rate to chilling stress.

Under some environmental conditions, dehydration is the first signal that induces the plant to respond (Figure 3) and the importance of the hydration state of tissues in the response of the plant to different stresses is well supported by experimental evidence (Matsuo et al., 2009).

At the transcriptional level, the heat-shock response is primarily regulated similarly to osmotic stress. The complex plant response to abiotic stress, which involves many genes and biochemical-molecular mechanisms, is schematically represented in Figure 4.

\section{Stress tolerance mechanism in crop}

The development of crop varieties (transgenic or non-transgenic) which can tolerate abiotic stresses would be of major benefit to agriculture in cropping regions where abiotic stresses are a chronic problem. Plants have developed various mechanisms to tolerate water or salt stress, including an altered shoot: root ratio, changing leaf orientation, alteration of membrane lipid composition or transpiration pulling. Thus, it is known that drought may cause a greater inhibition of shoot growth compared with root growth and, in some cases, the absolute root biomass in drying soil may increase when compared to well-watered soils (Santos et al., 2007). Also, illumination stress induces changes in the shoot: root ratio (Miralles et al., 2011). However, it is known that the degree of the responses of roots to abiotic stresses may vary considerably within a family, a genus, and even a species (Rahnama et al., 2011).

In drying soil, shoot growth can be limited as a result of hydraulic insufficiency and chemical signalling from the roots to the shoots via the xylem (Hsiao and $\mathrm{Xu}, 2000$ ). Over the last few years, progress has been made in understanding the biochemical and hormonal bases for the response of roots to stress conditions (Sangakkara et al., 2010). A central role has been attributed to abscisic acid (ABA), ethylene, reactive oxygen species, and reactive nitrogen species. IPT (isopentenyl transferase) was expressed in the whole plant, its maximal expression was attained during the drought episode and the transgenic plants displayed enhanced drought tolerance and superior yields (Figure 5).

On the other hand, root morphology determines the ability of the plant to acquire water and nutrients under water-stress conditions (Neumann, 2003). Deep rooting is also a critical factor in influencing the ability of a plant to absorb water from the deeper layers of the soil (Huang, 2008) found that deep rooting was essential to maintain cellular hydration by avoiding water-deficit in turf grass. Likewise, the greater number and 
lengths of the first roots of Zea mays seedlings under moisture deficits, as reported by Sangakkara et al., (2010), were beneficial for the plants to overcome stress. Branching of the roots and the total root length of vulgaris plants increased under moderate drought stress (Franco et al., 2008).

The hardening of roots, as revealed by an increased percentage of brown roots, is frequent in drought-stressed plants (Franco et al., 2006). This change in root colour from white to brown (and, in some species, with roots showing beads) was associated with suberisation of the exodermis, and may reflect a metacutisation process (Brundrett, 2002). Plant modification for enhanced tolerance is mostly based on the manipulation of genes that protect and maintain the function and structure of cellular components. In contrast to most monogenic traits of engineered resistance to pests and herbicides, the genetically complex responses to abiotic stress conditions are more difficult to control and engineer.

Fig.1 Common abiotic stresses in plants

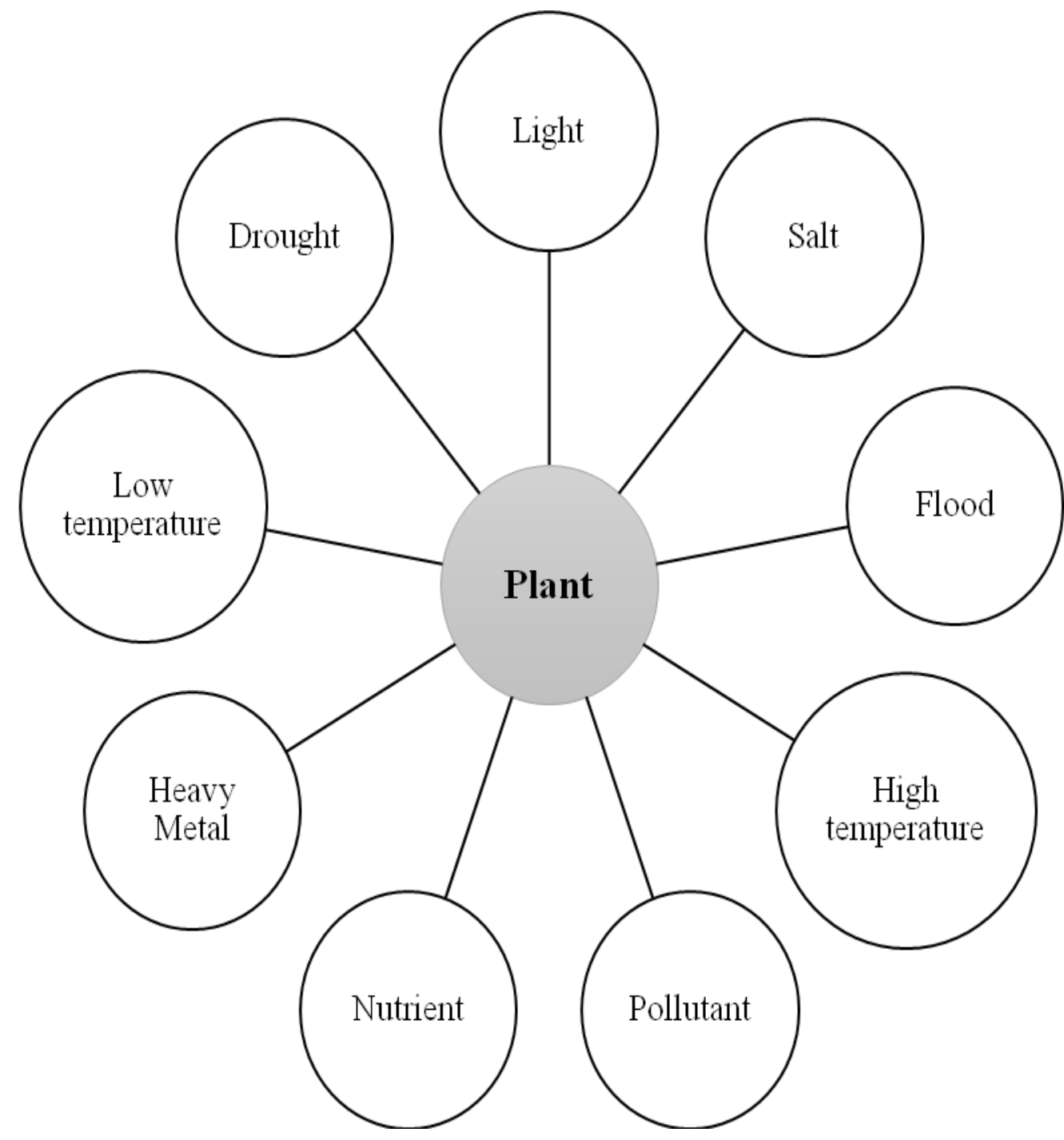


Fig.2 Plant responses to abiotic stresses

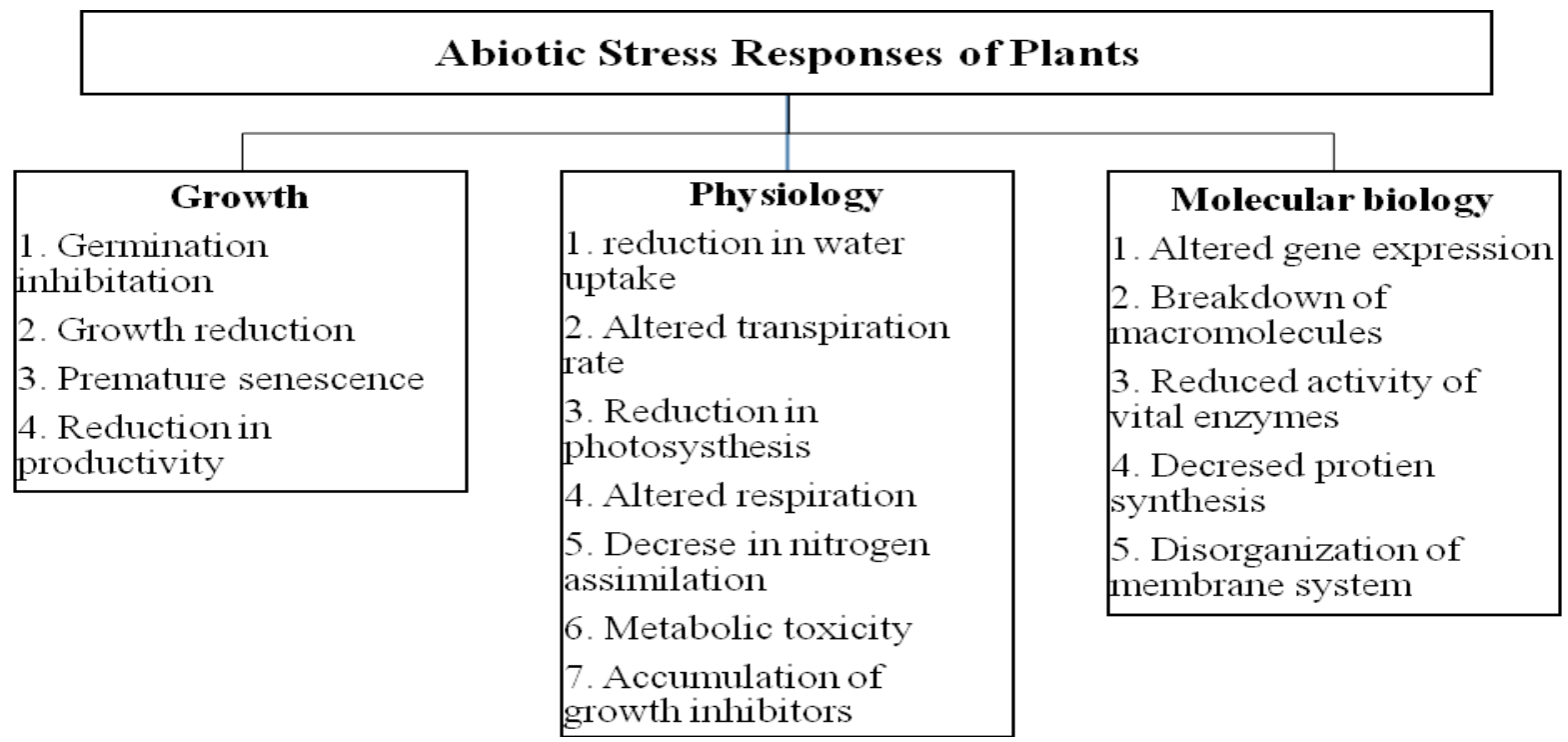

Fig.3 Growth of Arabidopsis seedlings on control (half-strength MS medium with $0.5 \%$ sucrose, $\psi w=-0.30 \mathrm{MPa})$ and PEG-infused or salt-containing plates, both having $\psi w=-0.75 \mathrm{MPa}$. Seeds were plated on each medium, stratified at $4^{\circ} \mathrm{C}$ for 3 days and seedlings grown for 7 days on vertically oriented plates before photographs were taken (Verslues et al., 2006)
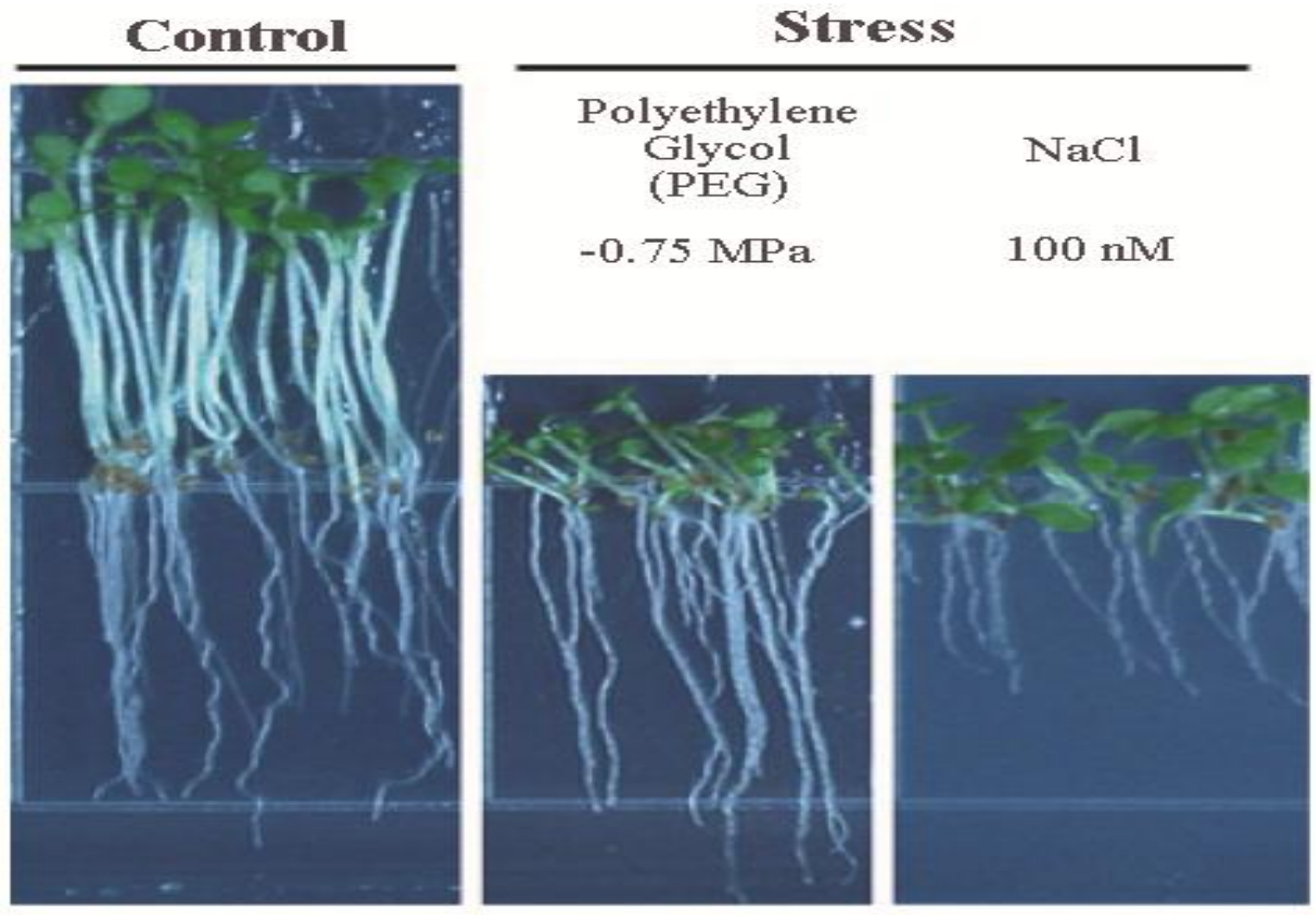
Fig.4 The complex plant response to abiotic stress (Wang et al., 2003)

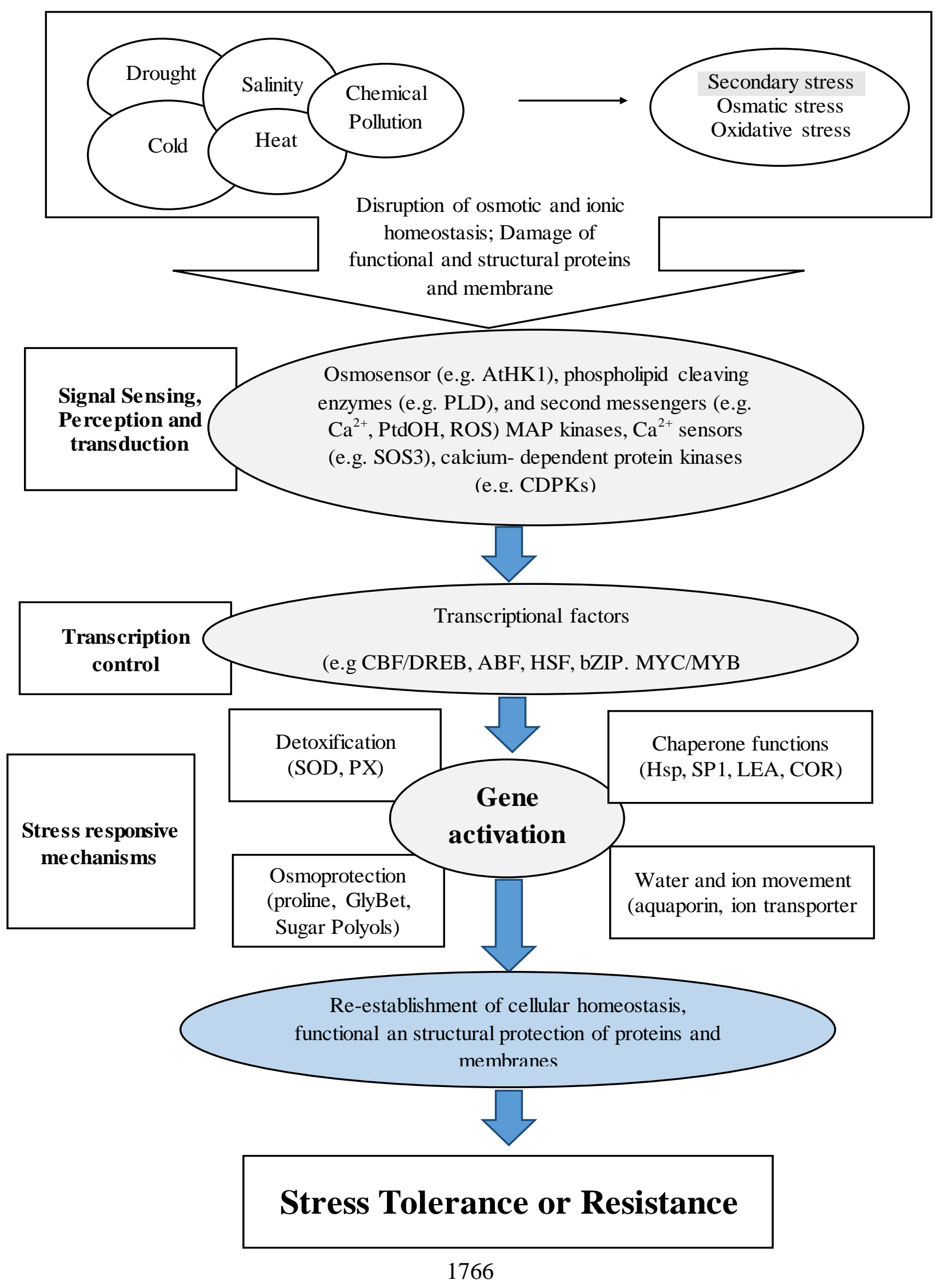


Fig.5 Effects of water-stress on growth of rice (Oryza sativa) plants. WT (Wild-type) and transgenic plants expressing PSARK (Senescence-Associated Receptor Kinase; a maturation-and stress-induced promoter): Isopentenyl Transferase (IPT) grown under well-watered conditions and plants subjected to water-stress at pre-anthesis follow re-watering as described (Peleg et al.,

\section{1}

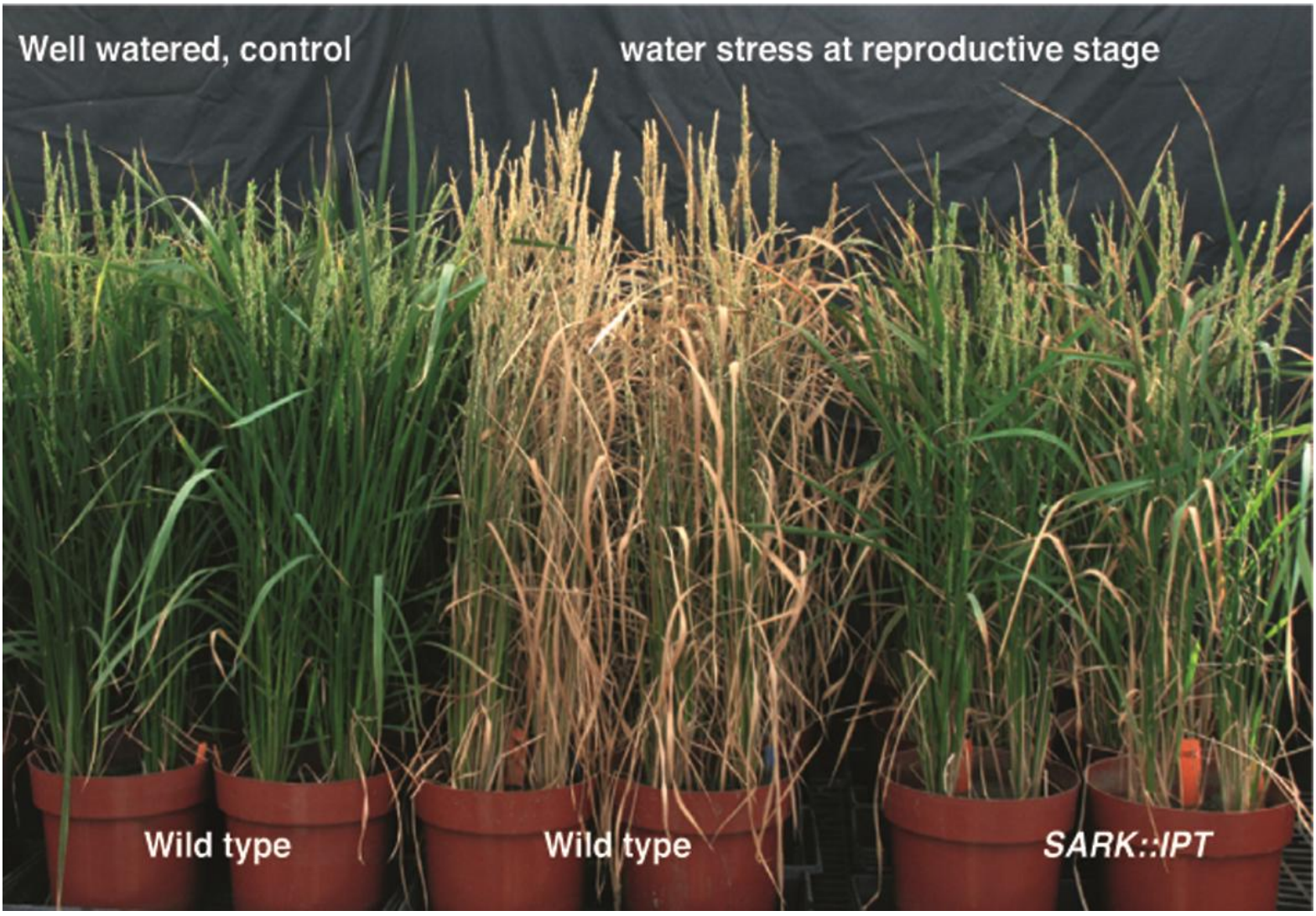

In addition to these, there are some major tolerance mechanism involved like Ion transporters, Osmoprotectants, free radical scavengers, late embryogenesis abundant proteins and factors involved in signalling cascades and transcriptional control are essentially significant to counteract the stress rate. In order to survive to heat stress, plants have various mechanisms such as scavenging of reactive oxygen species, production of antioxidants, maintenance of membrane stability, accumulation and adjustment of compatible solutes and most importantly chaperone signalling and transcriptional activation all the above mechanisms are regulated at the molecular level and enable the plant to flourish under stress condition.
In conclusion, according to Intergovernmental Panel on Climate Change 2012 (IPCC, 2012) temperature rising, drought, floods, desertification and deterioration of arable land and weather extremes will severely affect agriculture, especially in drought-prone regions of the developing world. Regarding food security, this threatening scenario highlights the need for a globally concerted research approach to address crop improvement to mitigate crop failure under marginal environments. One of the major goals of plant improvement is to develop crops fit to cope with environmental injuries but still capable to achieve substantial yield under abiotic stress. The emerging holistic system Biology approaches still enclose a 
myriad of unexploited resources for Plant and Agricultural Sciences.

\section{References}

Aroca R., Tognoni F., Irigoyen J.J., Sa' nchez-D1'az M. and Pardossi A. 2001. Different root low temperature response of two maize genotypes differing in chilling sensitivity. Plant PhysioBiochem, 39, 1067-1073.

Boyer J.S. 2009. Evans Review: Cell wall biosynthesis and the molecular mechanism of plant enlargement. FunctiPlant Bio, 36(5), 383-394.

Bray E.A. Bailey-Serres J. and Weretilnyk E. 2000. Responses to abiotic stresses. In Biochemistry and Molecular Biology of Plants. In: Gruissem, W. and Jones, R., Eds., American Society of Plant Physiologists, Rockville, 1158-1203.

Brundrett M.C. 2002. Coevolution of roots and mycorrhizas of land plants. New Phyto154: 275-304.

Franco J.A., Arreola J., Vicente M.J. and Martínez-Sánchez J.J. 2008. Nursery irrigation regimes affect the seedling characteristics of Silene vulgaris as they relate to potential performance following transplanting into semi-arid conditions. J Horti Sci Biotech, 83: 1522.

Franco J.A., Martínez-Sánchez J.J., Fernández J.A. and Bañón S. 2006. Selection and nursery production of ornamental plants for landscaping and xerogardening in semi-arid environments. J Horti SciBiotech, 81: 3-17.

Hsiao T.C. and Xu L.K. 2000. Sensitivity of growth of roots versus leaves to water stress: biophysical analysis and relation to water transport. JExper Bot, 51: 1595-1616.

Huang B.R. 2008 Mechanisms and strategies for improving drought resistance in turfgrass. Acta Horti, 783: 221-227.

Hummel I., Pantin F., Sulpice R., Piques M., Rolland G., Dauzat M., Christophe A., Pervent M., Bouteille M., Stitt M., Gibon Y. and Muller B. 2010. Arabidopsis plants acclimate to water deficit at low cost through changes of carbon usage: an integrated perspective using growth, metabolite, enzyme, and gene expression analysis. Plant Physio, 154(1): 357-372.

Machado R.M.A. and Serralheiro R.P. 2017. Soil Salinity: Effect on Vegetable Crop Growth. Management Practices to Prevent and Mitigate Soil Salinization. Horti, 3(2): 30 doi:10.3390/horticulturae3020030

Matsuo N., Ozawa K. and Mochizuki T. 2009. Genotypic differences in root hydraulic conductance of rice (Oryza sativa L.) in response to water regimes. Plant Soil 316: 25-34.

Miralles J., Martínez-Sánchez J.J., Franco J.A. and Bañón S. 2011.Rhamnus alaternus growth under four simulated shade environments: Morphological, anatomical and physiological responses. SciHorti, 127: 562-570

Neumann P.M. 2003. Transient resistance to root growth inhibition by moderate water stress: A possible explanation. In: Roots: The Dynamic Interface between Plants and the Earth. (Abe, J., Ed.). Kluwer Academic Press, Dordrecht, The Netherlands. Pp. 439-443.

Parent B., Hachez C., Redondo E., Simonneau T., Chaumont $\mathrm{F}$ and Tardieu F.2009. Drought and abscisic acid effects on aquaporin content translate into changes in hydraulic conductivity and leaf growth rate: a trans-scale approach. Plant Physio, 149(4): 20002012.

Peleg Z., Reguera M., Tumimbang E., Walia H. and Blumwald E. (2011) Cytokininmediated source/sink modifications 
improve drought tolerance and increase grain yield in rice under water-stress. Plant Biotech J, 9: 747-758

Rahnama A., Munns R., Poustini K. and Watt M. 2011. A screening method to identify genetic variation in root growth responses to a salinity gradient. $J$ Exper Bot, 62: 69-77.

Sangakkara U.R., Amarasekera P. and Stamp P. 2010. Irrigation regimes affect early root development, shoot growth and yields of maize (Zea mays L.) in tropical minor seasons. Plant, Soil Environ, 56: 228-234.

Santos T.P., Lopes C.M., Rodrigues M.L., Souza C.R., Silva J.R., Maroco J.P., Pereira J.S. and Chaves M.M. 2007. Effects of deficit irrigation strategies on cluster microclimate for improving fruit composition of Moscatel field-grown grapevines. SciHorti, 112: 321-330.

Shinozaki K., Yamaguchi-Shinozaki K. and Seki M. 2003. Regulatory network of gene expression in the drought and cold stress responses. Curr OpinPlant Bio, 6: 410-417.

Skirycz A. and Inze D. 2010. More from less: plant growth under limited water. $\mathrm{Curr}$ OpinPlant Bio, 21(2): 197-203.

Smirnoff N. 1998. Plant resistance to environmental stress. Curr OpinPlant
Bio, 9: 214-219.

Verslues P.E., Agarwal M., Katiyar-Agarwal S., Zhu J. and Zhu J. 2006. Methods and concepts in quantifying resistance to drought, salt and freezing, abiotic stresses that affect plant water status. Plant J, 45: 523-539. doi: 10.1111/j.1365-313X.2005.02593.x

Wang W., Vinocur B. and Altman A. 2003. Plant responses to drought, salinity and extreme temperatures: towards genetic engineering for stress tolerance. Planta, 218: 1-14.

Wang W., Vinocur B., Shoseyov O., Altman A.2004. Role of plant heat- shock proteins and molecular chaperones in the abiotic stress response. Trends Plant Sci, 9: 244-252.

Wang W.X., Vinocur B., Shoseyov O. and Altman A. 2001. Biotechnology of plant osmotic stress tolerance: physiological and molecular considerations. Acta Horti, 560: 285-292

Wells C.E. and Eissenstat D.M. 2003. Beyond the roots of young seedlings: the influence of age and order on fine root physiology. J Plant GroRegula, 21: 324-334.

Zhu J.K.2001. Plant salt tolerance. Trends Plant Sci, 6: 66-71.

\section{How to cite this article:}

Pratibha Kumari, Reena Kumari, Babloo Sharma, Saroj Kumar Prasad and Rajesh Kumar Singh. 2019. Abiotic Stress Response of Field Crops: Recent Approach. Int.J.Curr.Microbiol.App.Sci. 8(04): 1761-1769. doi: https://doi.org/10.20546/ijcmas.2019.804.205 